\title{
On the 90th birthday of Prof. Dr. Dr. h.c. med. vet. Johannes Eckert
}

\author{
Bruno Gottstein ${ }^{1} \cdot$ Peter Deplazes ${ }^{2} \cdot$ Horst Aspöck ${ }^{3}$
}

Published online: 1 June 2021

(C) The Author(s), under exclusive licence to Springer-Verlag GmbH Germany, part of Springer Nature 2021

Johannes Eckert, professor emeritus and parasitologist at the University of Zurich, member of the Leopoldina since 1988, celebrates his 90th birthday in May, 2021. On the occasion of this event, we wish not only to congratulate him, but also to express our appreciation for his extraordinary work as a researcher, teacher, and patron of science.

Johannes Eckert was born on May 14, 1931 in Silesia, where, because of the war, he had to interrupt his schooling. Then, starting in the autumn of 1944, he attended high school in Glauchau (Saxony) and completed the Abitur examination in 1950. Residing in the former GDR, Johannes Eckert stood in opposition to the regime at that time, and thus left the GDR in the spring of 1951. Subsequently, he obtained a degree in veterinary medicine at the University of Veterinary Medicine (TiHo) in Hannover. After finalizing his doctorate, he worked in a veterinary practice for 2 years. His scientific career began in 1958 at the Institute for Parasitology of the TiHo in Hannover, under the direction of Prof. Karl Enigk. With the support of a funding program from the German Research Foundation, he graduated in parasitology in 1967. This was followed by a research stay with Prof. Theodor von Brand at the National Institute of Health in Bethesda (MD, USA). During this time, Johannes Eckert developed a pronounced scientific interest in basic biological studies and applied medical research.

In 1968, the University of Zurich appointed Johannes Eckert as professor and director of the Institute for Parasitology, where he was promoted to a full

Horst Aspöck

horst.aspoeck@meduniwien.ac.at

1 Institute of Infectious Diseases, Faculty of Medicine, University of Bern, Bern, Switzerland

2 Institute of Parasitology, Vetsuisse-Faculty and Medical Faculty, University of Zurich, Zurich, Switzerland

3 Institute of Specific Prophylaxis and Tropical Medicine, Medical Parasitology, Medical University of Vienna, Vienna, Austria professorial position in 1975. By then, he had already begun to innovatively develop the institute and implement the far-sighted strategy of "One Health," as a joint facility of the veterinary and medical departments. The visionary structure of a double institute promoted a unique scientific and methodological enrichment of both sub-areas of parasitology. In compliance with modern scientific requirements, Johannes Eckert created a predominantly methodical research concept, which promoted the continuous integration of modern work approaches and innovative technologies.

Johannes Eckert's commitment to science and academia was remarkable. He assumed the management of numerous faculty and university committees, and from 1974 to 1976, he successfully led the Faculty of Veterinary Medicine of the University of Zurich as dean.

The breadth of his scientific output was enormous and included more than 300 publications. He also supervised numerous dissertations, five habilitation theses, and held hundreds of lectures. In addition, he was cofounder and main author of the internationally toppositioned "Lehrbuch der Parasitologie für die Tiermedizin" (in the meantime, the textbook has appeared in several English editions). His research activities on the so-called dangerous fox tapeworm Echinococcus multilocularis particularly stand out at the international level (Fig. 1). His experimental studies on chemotherapy of alveolar echinococcosis are among the most innovative in this area. The work continues to be the basis for clinical chemotherapeutic management of alveolar echinococcosis in humans worldwide. As a result, Johannes Eckert attained prominent international recognition through his establishment and long-standing leadership of the "Echinococcosis working group" within the framework of the World Health Organization (WHO) (Fig. 2). As a university teacher, he was bestowed with exceptional pedagogical skill, as well as the gift to formulate complex relationships concisely and print-ready. In teaching his subjects in a fascinating 


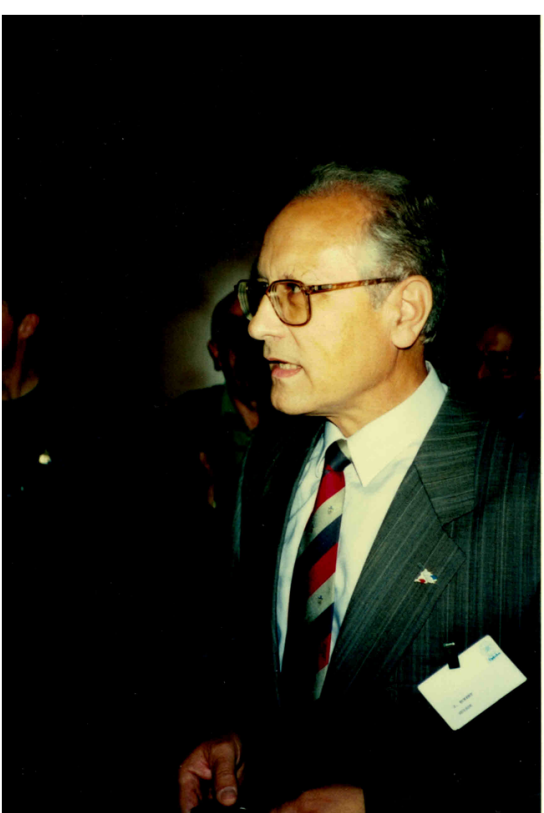

Fig. 1 Johannes Eckert at the 3rd International Symposium on Echinococcosis. Besançon - Arc-et-Senans, France, 1992/10/8 (photo archive H. \& U. Aspöck)

and highly motivating manner, he shaped generations of students of veterinary and human medicine.

The professional competence of Johannes Eckert radiated internationally, and resulted in numerous appointments to international organizations, scientific societies, and expert groups. In 1991, he was awarded an honorary doctorate from the University of Veterinary Medicine in Hannover. In the following years, Johannes Eckert received numerous other honors, such as the Rudolf Leuckart Medal from the German Society for Parasitology (1996) and the Walter Frei Award from the Vetsuisse Faculty (2004). He was elected Vice President of the "International Association of Hydatology" (1997) and awarded honorary memberships to

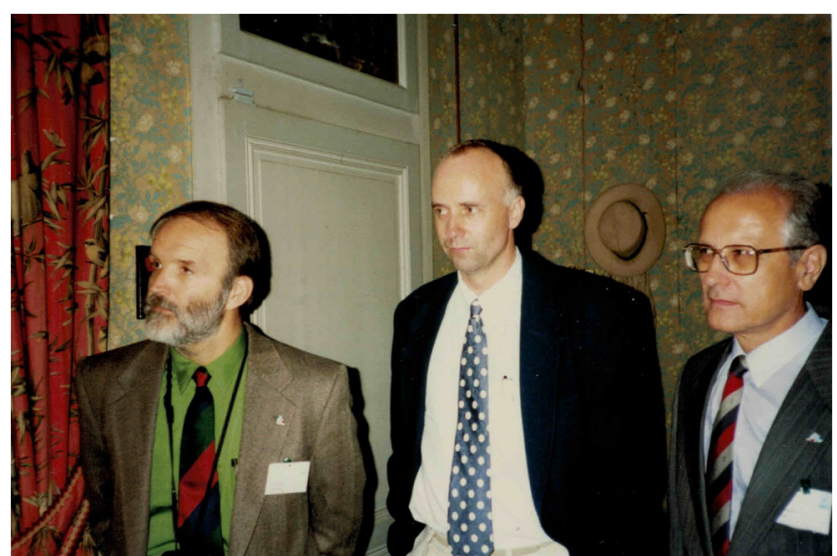

Fig. 2 Johannes Eckert (right), Peter M. Schantz (left), and Bruno Gottstein at the 3rd International Symposium on Echinococcosis. Besançon - Arc-et-Senans, France, 1992/10/8 (photo archive H. \& U. Aspöck) the World Association for the Advancement of Veterinary Parasitology (WAAVP, 1995), including national societies for parasitology in Poland (1998) and Slovakia (2000), as well as professional societies in Russia, Austria, Portugal, and Switzerland and the European Veterinary Parasitology College (EVPC, 2003).

In 1988, Johannes Eckert was elected member of the Deutsche Akademie der Naturforscher Leopoldina (German Academy of Natural Scientists; today German National Academy of Sciences Leopoldina). This was the beginning of an intensive engagement for various core aims of the academy throughout the following decades (Fig 3). He was vice-chairman and senator of the academy's section on "Veterinary Medicine", and from 1999 to 2004 member of the Executive Committee of the Academy. In 2001, the "Human Rights Committee" (HRC) of the Academy was instituted with Johannes Eckert as one of its leading founders, and from 2004 to 2010 accordingly chairman of the HRC. The HRC campaigns for scientists across the world who suffer from prosecution (usually by their own governments) in connection with human rights violation. Johannes Eckert developed an extremely intensive working relationship with the HRC. He initiated a series of symposia, "Human Rights and Science", and succeeded in establishing cooperation in this field between the academies of numerous European countries (Figs. 4, 5). Since then, eight symposia have been organized in several countries with an increasing number of delegates. Aside from the enormous significance of his scientific research, as well as in medical and veterinary parasitology in the broadest sense, Johannes Eckert has achieved outstanding merits through his manifold efforts to provide support and protection to oppressed scientists and people in general.

Johannes Eckert is a very judicious person and, if necessary and appropriate, he does not spare to be firm and authoritarian.

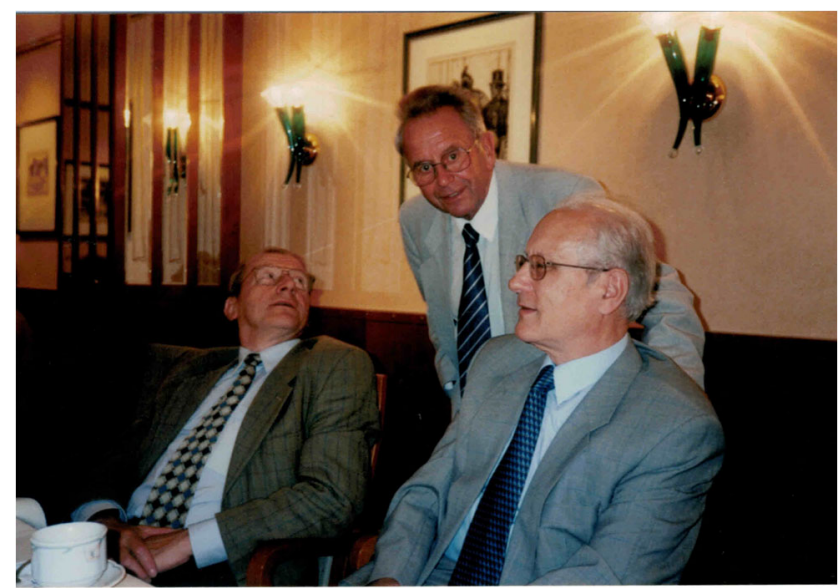

Fig. 3 Johannes Eckert (right), Benno Parthier (left), and Theodor Hiepe at the Symposium "Parasitism as a Strategy of Life" of the German Academy of Naturalists Leopoldina. Halle (Saale), Germany, 1999/09/ 15 (photo archive H. \& U. Aspöck) 


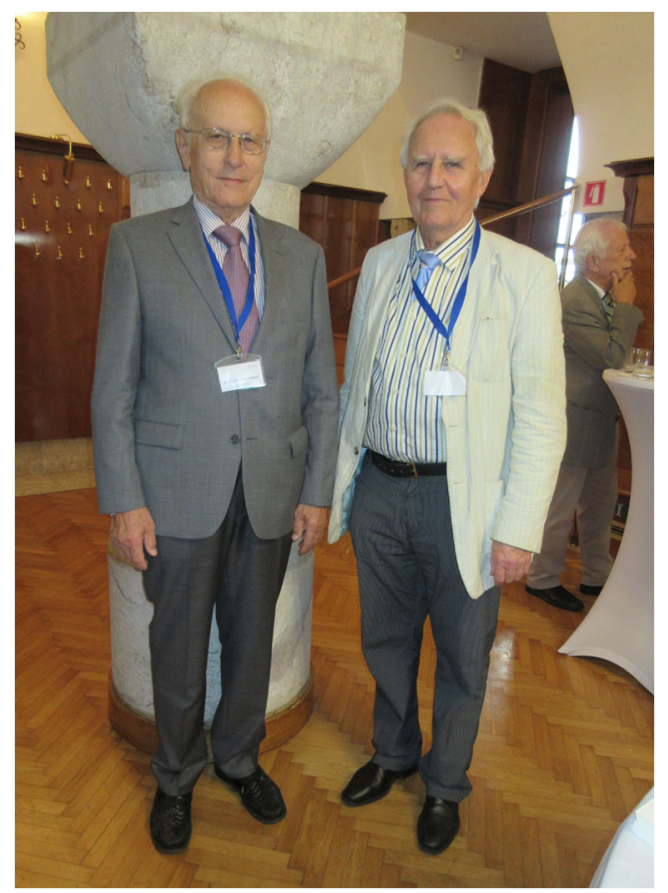

Fig. 4 Johannes Eckert (left) and Horst Aspöck at the 6th Symposium "Human Rights and Science" of the Human Rights Committee (HRC) of the German National Academy of Sciences Leopoldina. Ljubljana, Slovenia, 2016/09/30 (photo archive H. \& U. Aspöck)

Thus, he obtains the highest respect from all of his partners and colleagues. After his emeritation in 1997, he continued to maintain a close relation to "his" Institute, attending its sem-

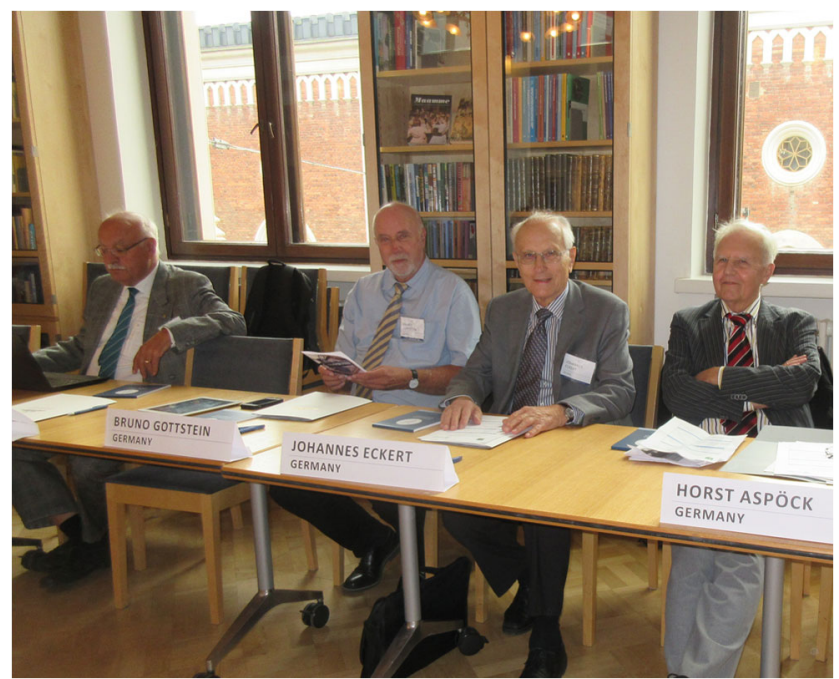

Fig. 5 Johannes Eckert (middle), Bruno Gottstein (left), and Horst Aspöck at the 7th "Human Rights and Science" Symposium of the Human Rights Committee (HRC) of the German National Academy of Sciences Leopoldina. Helsinki, Finland, 2017/09/28 (photo archive H. \& U. Aspöck) inars and contributing with not only constructive but also critical questions and comments. Until last year, he was very committed and supportive in preparing the 4th edition of the textbook "Parasitologie für die Tiermedizin", by sharing his long-standing and high degree of competence in the field of parasitology.

Of the three co-authors of this laudation, two (B.G. and P.D.) were students, scholars, assistants, and finally colleagues of Johannes Eckert, and both have become professors of parasitology at the University of Bern and Zurich, respectively. The third author (H.A.), a bit younger than the jubilarian, is an old colleague and friend, who has - from the first meeting until today-always admired the unusual intellectual capacity, the enormous scientific knowledge, academic education, outstanding morality, and impeccable integrity of Johannes Eckert. All three of us are immensely grateful for having met this giant of a man.

Dear Johannes, to this day, we appreciate not only your high level of competence as a colleague, but especially also your cordial involvement in maintaining friendships and comradeship with all of your working colleagues.

For further reading:

Deplazes P, Gottstein B (2006) The 75th birthday of Prof. Dr. Dr. h.c. med. vet. Johannes Eckert. Schweizer Archiv für Tierheilkunde 148: 443-445

Eckert J (2020) Beitrag zur Geschichte des Instituts für Parasitologie der Veterinärmedizinischen und der Medizinischen Fakultät der Universität Zürich (IPZ) 1968-1997. Universität Zürich 86 pp

Hacker J, Lutz H (2011) Johannes Eckert (Zürich, Schweiz) [zum 80. Geburtstag]. Leopoldina-Jahrbuch 207-209

Ter Meulen V, Hiepe T (2008) Laudatio für Herrn Professor Dr. Johannes Eckert ML anlässlich der Verleihung der Leopoldina-Verdienstmedaille. Jahrbuch 2007 der Deutschen Akademie der Naturforscher Leopoldina (Halle/Saale) LEOPOLDINA (R. 3) 53: 175-177

Publisher's note Springer Nature remains neutral with regard to jurisdictional claims in published maps and institutional affiliations. 